Cuad. invest. hist. Brocarn. 17 (1991). Págs. 141-151.

\title{
1936: UN EJEMPLO DE REPRESIÓN JURÍDICO-POLÍTICA DE LA MASONERÍA ESPAÑOLA
}

\author{
José Miguel Delgado Idarreta ${ }^{\star}$
}

\begin{abstract}
RESUMEN.-Elarticulo presenta la represión que se llevó a cabo desde la España nacional del General Franco iniciada la guerra civil. La creación del contubernio, la Leyde Responsabilidades Politicas de 1939, la Leyde Represión de la masoneria y el comunismo de 1 de marzo de 1940 y la formación de la «Causa General»por undecreto del Ministerio de Justicia de 26 de abril de 1940 componen la trama que se servirápara organizar la represión franquista en los años inmediatos al fin de la guerra civil. En concreto se analiza la "Pieza Especial» de la "Causa General» que se incoa para esclarecer los «antecedentes yasesinatos de DonJoséCalvo Soteloy DonJoséAntonio Primode Rivera» (sic).
\end{abstract}

SUMMARY.-Thisarticle describesthe repressiondeveloped in Franco'snationalist Spain, which was a reality from the very begginig of the Civil War. The creation of the "contubernio», the 1939 Ley de Responsabilidades Politicas, Bill of Political Responsibilities, the Ley de Represion de la masoneria y el comunismo Bill for the Repression of Masonry and Comunsm - promulgated on March Ist 1940-, and the opening of the "Causa General». General Cause, throung a decree emitted by the Ministry of Justice are the elements which formed the scheme which would be used in order to organize the repression in the yearsinmediately after the end of the CivilWar. This paperincludes an analysis of the Pieza Especial -a part of the General Causewhich was started wit the purpose of clarifying the previous foregoings and the killings of Don José Calvo Sotelo and Don José Antonio Primo de Rivera.

Palabras clave: 1936, Represión, Masonería, Guerra Civil, Causa General.

Key words: 1936, Repression, Masonry, Civil War, General Cause.

\footnotetext{
${ }^{*}$ Universidad de Zaragoza. Campus de la Rioja.
} 


\section{JOSÉ MIGUEL DELGADO IDARRETA}

\section{INTRODUCCIÓN}

La Dictadura del General Primo de Rivera (1923-1930) había gobernado sin transformar ni la esencia de la Restauración ni los métodos de gobierno imperantes hasta entonces y sus proyectos económicos \pm terminaron siendo tachados de megalómanos, ya que lo único que perseguian eran «costosas manifestaciones de prestigio» ${ }^{1}$; su programa social había anunciado la supresión de clases, pero a su caída en 1930 el conflicto social había seguido conservando la problemática anterior; el problema regional sólo provocó que catalanes y vascos se hicieran sospechosos y así «la unidad moral española se vio mas amenazada» ${ }^{2}$. El fracaso político era cada vez más evidente y Primo de Rivera, debió retirarse el 30 de enero de 1930, muriendo poco después en el exilio en París.

La semidictadura de su sucesor el general Berenguer solo podia ser una etapa de transición, a la vez que los viejos partidos políticos resucitaban: moderados, radicales, catalanistas republicanos, socialistas, antimonárquicos en general firmaban el Pacto de San Sebastián para implantar la República.

Tras las elecciones del 14 de abril de 1931 se iniciaba la II República (1931-1936) que nacía bajo los auspicios de que algo debía cambiar. Los resultados de las elecciones de junio a Cortes Constituyentes aseguraban la orientación reformadora al dar la mayoría a la unión de republicanos y socialistas. Pero si la idea de transformación definiría los años republicanos, la idea de gobernar se consiguió dificilmente.

La II República se iniciaba, tras la elección de las Cortes Constituyentes, con la obligación de darse una Carta Magna que se tradujo, tras unos meses de arduos trabajos ${ }^{3}$ en la Constitución de 1931. Desde el primer momento la masonería española reaccionó a favor de tal proyecto y así la Gran Logia Española veía con satisfacción el proyecto pues «algunos de los puntos acordados en dicha Gran Asamblea ha sido ya recogidos en el proyecto de Constitución.... ${ }^{4}$ y el Boletín Oficial de la Gran Logia Española en su número 8 de primer semestre de 1931 comentaba con sosiego los principales puntos de las discusiones estando seguro que «sobrarían votos» si todos los diputados francmasones -escribe V. Costa - la votaban ${ }^{5}$.

Es el punto de partida para que se inicie la obsesión del contubernio. Así cuando se produzca el pronunciamiento de julio de 1936 la persecución, la represión jurídicopolítica que se va a ejercer sobre los masones va a ser implacable. La masonería española deberá responsabilizarse de todos los males de España. Durante la Guerra Civil se irá

1 Vilar, P. Historia de España. Barcelona, 1978, p. 121.

2 Ibidem, p. 122

3 Del 29 de julio en que se constituye la Comisión Parlamentaria encargada de redactar el proyecto de Constitución hasta mediados de diciembre de 1931 en que era aprobado definitivamente.

4 Archivo Histórico Nacional. Salamanca (AHNS), leg. 371, exp. 16.

5 Arbeloa, V.M. «La Masonería y la ley de congregaciones religiosas» en La Masonería en la Historia de España, Actas del I Symposium de Metodología Aplicada a la Historia de la Masoneria Española. Zaragoza, 1985, p. 172. 
recogiendo toda la documentación masónica, entre otras, en todos los lugares en que las tropas del General Franco se posicionen. Toda esa documentación será depositada en lo que hoy es el Archivo de la Guerra Civil dependiente del Archivo Histórico Nacional en Salamanca. Fuente inexcusable para trabajar sobre el tema, aunque no la única ni el único archivo ${ }^{6}$.

Como bien sabemos el Régimen del General Franco (1936-1975) se configura en sus tres primeros años bajo una guerra civil, pero que, como podemos comprobar, se dilata a la largo de casi medio siglo representando prácticamente casi la mitad del actual siglo XX en la Historia de España.

\section{LA REPRESIÓN}

Como acabamos de indicar desde el primer momento el franquismo reacciona en contra de cualquier partido y agrupación político o social «que desde la convocatoria de las elecciones celebradas en fecha de 16 de febrero del corriente año (1936) han integrado el Frente Popular, así como cuantas organizaciones han tomado parte en la oposición hecha a las fuerzas que cooperan al movimiento nacional» ${ }^{7}$. Pero explícitamente referido a la masonería es el Decreto dado en Santa Cruz de Tenerife dos días después del anterior en el que se dice que es contraria a la ley al igual que «otras asociaciones clandestinas» y sus miembros se consideran sujetos de un crimen de rebelión ${ }^{8}$. Posteriormente en una orden de 10 de enero de 1937 se señalan las organizaciones, agrupaciones o partidos que se encuentran inmersos en la ley se descalifican de forma total, aunque no se cita literalmente a la masonería ${ }^{9}$, como tampoco aparece mencionado expresamente la masonería en la ley de Responsabilidades Políticas de 9 de febrero de $1939^{10}$. Toda esta normativa culminará con la ley sobre Represión de la masonería y del Comunismo de 1 de marzo de 1940 constituyéndose un Tribunal Especial que estaria en vigor hasta $1946^{11}$. Comple-

6 Díez de los Ríos, M.! T. «Fondos de la Masoneria en la Sección Guerra Civil» del Archivo Histórico Nacional Salamanca en La Masonería en la Historia de España. Actas del I Symposium de Zaragoza, 1985, pp. 335-348. Martínez Millán, J. «Fuentes para el estudio de la Masonería en la Sección de Inquisición del Archivo Histórico Nacional». Ibídem. En este citado I Symposium toda una Sección del mismo se dedicó enteramente a Fuentes. Delgado Idarteta, J.M. y Navajas Zubeldía, C. «Fuentes para el estudio de la reacción franquista antimasónica» en Actas IV Symposium de Metodología Aplicada a la Historia de la Masonería Española, celebrado en Alicante 26-30 setiembre, 1989. Alicante, 1990, pp. 947-958. Sánchez Recio, G. Y Santacren Soler, J.M. «La Causa General, fuente para el estudio de la rebelión y de la Guerra Civil», en Arbor diciembre-1986, pp. 217-230, entre otros trabajos.

7 Boletín Oficialde la Junta de Defensa Nacionalde España. Burgos, 16 de setiembre de 1936, n. 22. El Decreto era el n.o 108 de la Presidencia de la Junta de Defensa Nacional y estaba firmado por Miguel Cabanellas.

8 Ferrer Benimeli, J.A. Masonería Española Contemporánea. T. II,p. 140.

9 Boletín Oficial del Estado (B.O.E). Burgos. n..$^{2} 83$ del 11 de febrero de 1937. año II.

10 B.O.E. Burgos, n. 44 de 13 de febrero de 1939, año IV.

11 El Tribunal Especial vería solamente casos de masoneria y comunismo; en una primera época fue presidido por el General Saliquet y se le sustituyo en 1963 por el Tribunal de Orden Público. Ver Hidalgo Nieto, V. «La represión masónica en Asturias» en La Masoneria en la Historia de España, Actas del ISymposium ...,Zaragoza, 1985, pp. 189-199. Uso I Arnal, J.C. «Nuevas aportaciones sobre la represión de la masonería española tras la Guerra Civil» en Masonería, politica y sociedad. Actas III Symposium C.E.H.M.E.,Zaragoza, 1989, pp.599-647. 


\section{JOSÉ MIGUEL DELGADO IDARRETA}

mentado por la formación de la Causa General por un decreto del ministerio de Justicia de 26 de abril de $1940^{12}$.

No solo fue la masonería perseguida, sino que cualquier excusa es buena, para que quien no siga al pie de la letra todas las normas dictadas por el «nuevo orden», dado que la represión y la censura abarcaron todas las instancias sociales, sea acusado de masón y apeado de su cargo e incluso desterrado y esto en el mejor de los casos pues la mera sospecha de masón era suficiente para poder terminar ante un pelotón de fusilamiento. Así por ejemplo «el 7 de julio de 1941 Gregorio Salvador y Merino fue destituido como delegado nacional de sindicatos» porque alguien difundió una supuesta conexión con la masonería, aunque la noticia no la recogió la prensa hasta diciembre de ese año, dándosele, incluso, baja del partido único: Falange Española ${ }^{13}$. También los ataques se dirigieron contra la actividad de D. Juan, padre del Rey de España D. Juan Carlos I, llamándole «ambicioso» $\mathrm{y}$ «traidor» $\mathrm{y}$ acusándole de «afiliación masónica» ${ }^{14}$.

El problema de toda esta represión, sin olvidar la que existió en el campo republicano incontrolada y desordenada que recaía sobre personalidades conocidas y que el régimen de Franco se encargó de explotar «diariamente por medio de la prensa, las conmermoraciones y los hábitos de vocabulario» ${ }^{15}$, es que se ejecutaban en orden y cumpliendo órdenes por iniciativa falangista o represión militar, que fue muy dura en los primeros días del inicio del golpe militar por simple delitos de opinión, que se perpetuó mucho tiempo y sobre todo «sobrevivió a la guerra» y «el espectáculo de las prisiones y campos de concentración, y de la presión moral sobre las víctimas, está aún vivo como testimonio» ${ }^{16}$.

\section{LA GUERRA CIVIL ESPAÑOLA}

Es uno de los periodos mas estudiados de la historia de España y el momento de la represión mas real. Por orden de 8 de noviembre de 1939 (terminada la guerra, como puede notarse) se creó el Archivo de la Guerra de Liberación dentro del Archivo Histórico Militar de Madrid con el cometido de «contribuir a la difusión de la cultura militar histórica en el Ejército» ${ }^{17}$. Dentro de él aparece la denominada Documentación Roja y en su interior se pueden encontrar las carpetas denominadas «Antecedentes políticos de la Guerra de Liberación-Masonería ${ }^{18}$. Documentación en la que no voy a

12 Sánchez Recio, G. y Santacren Soler, J.M. Op. cit., pp. 217-230.

13 Sinova, J. La censura de prensa durante el Franquismo. Espasa-Calpe. Madrid-1989, p. 184.

14 Ibídem, p. 217. El artículo lo firmó el mismo Franco en el periódico Arriba en 1949 con el seudónimo Jakim Boor, aunque ya Luis Carrero Blanco en 1947 bajo el seudónimo Guinés de Buitrago en un artículo titulado «Revuelo de mandiles» identificaba Monarquí y masonería, y Juan Aparicio en 1943 en El Español había difundido un documento masónico en apoyo a Don Juan.

15 Villar, P. Op. cit., pp. 150-152.

16 Ibídem.,p. 152.

17 Salas Larrazabal, R. «Los archivos para la Historia de la Guerra Civil»en Los archivos para la Historia del siglo XX. Ministerio de Cultura, Madrid-1980, p. 118.

18 Delgado Idarreta, J. M. y Navajas Zubeldía, C. Op. cit., pp. 948 y 949-955. 
extenderme, ya que sobre su contenido hemos hablado en otra parte, aunque si quiero destacar algún aspecto como que la documentación recogida se inicia en 1929, periodo de la dictadura de Primo de Rivera, y hace alusión a una propuesta de la logia Italia de la obediencia de la Gran Logia de Francia teniendo como argumento central «el restablecimiento del poder temporal del Papa» en Italia y sus consecuencias internacionales ${ }^{19}$. Repercusiones internacionales claras hasta el punto que la Acción Católica en el mundo edita una serie de artículos que tienen como base el trabajo de Juan Guiraud redactor-jefe de «La Croix» sobre el acuerdo entre el Vaticano y el Quirinal en los que se explica como Mussolini se ha decidido por la Iglesia «a causa de haber advertido que la masonería es una obra de decadencia y destrucción» ${ }^{20}$. Esta carpeta 9 abarca hasta 1936; la Carpeta 10 amplia la documentación masónica hasta 1939, es decir la primera de ellas retoma todo lo referente a la II.- República desde los momentos finales de la Dictadura de Primo de Rivera y la segunda abarca toda la guerra civil y lógicamente todo es bueno para acusar y hacer responsable a la masonería de todo lo ocurrido desde cuando escriben que es necesaria una «reparación inmediata» de los "postulados morales» profesados por la Institución masónica ${ }^{21}$ hasta la plancha en que se analiza el estado de la masonería en España ${ }^{22}$ o como debe ser la militancia de masones en el «partido llamado Republicano Liberal Demócrata» ${ }^{23}$ pasando por la petición de indul$\operatorname{tos}^{24}$ la protesta del restablecimiento de la pena de muerte ${ }^{25}$ o que «el pueblo español no caiga en el profundo error de combatirse una vez terminada la lucha actual» ${ }^{26}$ a lo que el régimen de Franco no solo hizo caso, sino que incluso esta advertencia se volvió contra la masonería.

\section{LA CAUSA GENERAL Y LA MASONERIA}

El centro documental mas interesante para este trabajo es la denominada Causa General que surge para permitir «apreciar en conjunto la delincuencia habida en cuanto a su preparación, extensión, intensidad, organización, procedimiento, inspiración y dirección» en todo el territorio nacional durante «la dominación roja» ${ }^{27}$.

19 Servicio Histórico Militar. Archivo de la Guerra de Liberación Documentación Roja (citaré D. R.) armario 47, leg. 74, carpeta 9, docs. 2-5.

20 Diario de La Rioja de 2 de marzo de 1929. El artículo aparece bajo el epigrafe «La masonería vencida».

21 D.R. Carpeta 9, docs. 12-15 de Valles de Vigo de 22 de diciembre de 1933.

22 D.R. Carpeta 9, docs. 16-17 de la logia Constancia n. 13 de Orense de 28 de diciembre de 1933.

23 D.R. Carpeta 9, docs. 21-22 de Valles de Gijón de 15 de noviembre de 1933 firmado por el Gran Secretario, Antonio L. Villar, y el Gran Maestre Regional, Rogelio García.

24 D.R. Carpeta 9, docs. 24 y 27 de la Gran Logia de Cataluña de 24 de noviembre de 1934 y del Soberano Consejo de Gobiemo de la G.L.E. de 7 de noviembre de 1934.

25 D.R. Carpeta 9, docs. 25-26 del Soberano Consejo de Gobierno de la G.L.E. de 12 de abril de 1934.

26 D.R. Carpeta 10, docs. 3 de la Logia Plus Ultra firmado en París el 4 de enero de 1937.

27 B.O.E. de 4 de mayo de 1940. 


\section{JOSÉ MIGUEL DELGADO IDARRETA}

El último de los documentos de esta «Pieza Especial» de la Causa General data de 1970 y hace referencia a «Máximas e instrucciones políticas para el Gran Oriente español y logias de la Masonería egipciana» ${ }^{28}$. Pero la parte fundamental hace alusión a un debate de las Cortes a través de su reproducción en el Diario de Sesiones en relación a la masonería en la que el diputado Ventosa explica que uno de los problemas planteados en España «es este de la infiltración de la masonería en todos lo órganos del Estado, incluso de los militares» y si la represión de octubre de 1934 hubiera sido eficaz «el separatismo y el marxismo revolucionario se hubiera podido extirpar» ${ }^{29}$. No olvidemos que el Presidente del Gobierno Lerroux había subido al poder a raíz de la revolución indicada y que una vez más, como queda patente en las palabras del diputado Ventosa y de los que le apoyaron Calvo Sotelo, Lamanié de Clairac, Gil Robles, Martínez de Velasco en esta sesión, masoneria, separatismo y marxismo caben todos en el mismo saco y que se trataba de inculpar a la masonería del «mal estado» de España y por tanto de la necesidad de justificar el golpe de Estado de 1936.

De ahi a responsabilizar a la masonería y a masones concretos del asesinato de Calvo Sotelo sólo hay un paso como ahora veremos.

\section{MASONERÍA Y ASESINATO de CALVO SOTELO}

El resto de la documentación de esta «Pieza Especial» es relativa a los «Antecedentes y asesinatos de Don José Calvo Sotelo y Don José Antonio Primo de Rivera» ${ }^{30}$. Centraremos la explicación sólo en el caso del asesinato de José Calvo Sotelo, pues aunque se cita también a José Antonio Primo de Rivera no hay ni una sola alusión a él en el interior de la documentación.

En esta documentación se hacen responsables directos del asesinato de José Calvo Sotelo el 12 de julio de 1936 a los masones José Alonso Mallol, José Garriga Pato, Manuel Azaña Díaz, Lorenzo Aguirre Sánchez, Ricardo Burillo Shtolle y Santiago Casares Quiroga.

En el Parlamento del Frente Popular se llegó a los máximos de tensión política. Por una parte José Antonio Primo de Rivera no había conseguido ser elegido diputado y desprovisto, por lo tanto, de su inmunidad parlamentaria el Gobierno se apresuró a encarcelarlo, junto a sus colaboradores más próximos, al ser el creador de Falange Española con características similares a los fascistas italianos de Mussolini y a los nazis alemanes de Hitler, atacando el egoísmo burgués y al internacionalismo marxista a la vez que se estructuraba sobre las viejas tradiciones imperialistas españolas de los siglos XVI y XVII acentuando lo nacional en contra de los «separatismos» ${ }^{31}$. Por otra José

28 Archivo Histórico Nacional (AHN) Sección Fondos Contemporáneos.Fondo Causa General. Madrid, Pieza Especial, caja 1500 (1).

29 Diario de Sesiones de Cortes, n. 146 de 23 de enero de 1935.

30 AHN. Causa General, pieza especial, caja 1500 (1).

31 Seco Serrano, C. y otros. «Historia de España» Barcelona, 1966, pp. 792-793. El pretexto de su encarcelamiento fue el de tenencia ilícita de armas, sería ejecutado el 20 de noviembre de 1936 en la cárcel de Alicante. 
Calvo Sotelo como jefe del Bloque Nacional se constituyó en «implacable denunciador de las violencias que estaban acabando con toda posibilidad de equilibrio" y así centró en su persona toda «la animosidad de la mayoría parlamentaría que veía en sus palabras una incitación dirigida al estamento militar para lanzarlo al golpe de Estado» ${ }^{32}$. Ello le llevó a ser asesinado como aparente «venganza» del asesinato del Teniente Castillo unos días antes.

\section{LOS INCULPADOS}

Esta documentación tiene dos partes. La primera bajo el sello de secreto y remitida por la Dirección General de seguridad del Ministerio de la Gobernación y dirigido al Fiscal Instructor de la Causa General con sede en el palacio de Justicia de Madrid se guardan las copias de los oficios de los supuestos seis implicados directos en el asesinato de Calvo Sotelo junto con la ficha masónica correspondiente. Figuran como urepublicanos en acción» Alonso Mallol, Garriga Pato, Casares Quiroga, como simple republicano Murillo Shtolle, como comunista Aguirre Sánchez, no se dice nada de Azaña Díez. Del primero de estos, Alonso Mallol se indica que es el «máximo responsable del asesinato..., según confidencia de S.I.P.M.» ${ }^{33}$. Dirigido al mismo fiscal, pero esta vez desde la Delegación del Estado para la recuperación de documentos en Salamanca se remitan «seis informes positivos de antecedentes masónicos de todos ellos»" ${ }^{34}$.

La pesquisa subsiguiente era la de conocer la realidad de cada uno de estos seis implicados, para lo que recurrí al Archivo de la Guerra Civil en Salamanca a los expedientes del Tribunal Especial para la Represión de la Masonería y el Comunismo.

\section{José Garriga Pato}

Se le incoó el expediente por el juzgado especial del Tribunal el 11 de abril de 1945. Había pertenecido a la logia Liberación n.o 47 de Málaga con el simbólico BRETON donde fue iniciado el 9 de mayo de 1935 y dado de alta en Grupo n.o 1 de Valencia el 15 de enero de 1937, durante la República ejerció de policía en Málaga, al ser hecho prisionero vivía en Madrid como comisionista. Se le tenía por afiliado a Izquierda Republicana y se dice de él «que se dedicó a denunciar a compañeros de derechas y a perseguirles» y llegó a Teniente ayudante de Batallón de Enlace rojo. En 1946 se encontraba en la cárcel Central de Alcalá de Henares. En su declaración reconoce haber sido iniciado, negándose a delatar a nadie. El 31 de julio de 1946 se le declara responsable pero «dadas las circunstancias del caso y la falta de peligrosidad - se acordó libertad provisional - con la obligación de presentarse en este juzgado cuantas

32 Ibídem, p. 793.

33 AHN. Causa General, Pieza Especial. Caja 1500 (1), doc. 9.

34 Ibidem, doc. 23. 
veces fuese llamado y de comunicar todos sus cambios de domicilio», pero para el momento llevaba ocho años de prisión por «asociación ilegal». Falleció el 25 de septiembre de 1947 en el Sanatorio Penitenciario de Cuellar, a pesar de que, como hemos indicado, se le había acordado la libertad provisional que no se cumplió dejando mujer, Monserrat Giral y dos hijos. La contradicción final es que el proceso fue sobreseido el 22 de mayo de $1948^{35}$.

\section{José Alonso Mallol}

Se le incoó expediente el 27 de enero de 1949 y figura iniciado en 1916 con el simbólico DEMOLINS en la logia Constante Alona de Alicante, siendo su paradero desconocido en el momento de abrirse el expediente.

Fue presidente del Consejo Provincial de Izquierda Republicana siendo responsable «del asesinato de D. José Calvo Sotelo y existiendo pruebas de su intervención en el de la Srta. Josefina Aramburu», pero no se pudo ampliar ninguna diligencia hasta el punto que las actuaciones seguidas contra él fueron «archivar provisionalmente» el once de junio de 1949, escasamente seis meses más tarde del inicio de la acusación de rebeldía, que es por lo que se persiguió ${ }^{36}$.

Fue denunciado como masón por Fernando Aguilo Planells (8-V-1940) Juan Martín de Santa Olalla y Ezquerro (21-IV-1940). Luis Curiel Barragán, José Pérez García (3VI-1940) ${ }^{37}$.

\section{Ricardo Murillo Shtolle}

Se incoó su expediente el 15 de febrero de 1946, pasó a la fiscalía el 29 de mayo y el 22 de junio se acordó archivar las diligencias por "presunto fallecido».

Era Comandante de Asalto, luego ascendió a Teniente Coronel «con mando en las fuerzas rojas». No consta su adscripción a la masonería, aunque se dice de la existencia de una circular de 6 de agosto de 1936 de la Gran Logia Regional del Centro relativa a masones que se encuentran luchando en distintos frentes, entre los que figura en el frente de Guadarrma, ademas de la declaración que hizo el Coronel del Ejército Aurelio Martín Arcediano en 1941. Absurda la delación y absurda la incoación de expediente, pues como queda dicho y unido a este existe un documento RESERVADO del Consejo Superior del Ejército en el que consta que fue condenado a la última pena y cumplida en Madrid el 21 de julio de 1939, tras haber sido preso en Alicante acusado de ser Coronel de Ejército de Extremadura y Jefe Superior de Policía de Cataluña, aunque no

35 AHN. Tribunal Especial para la Represión de la Masoneria y el Comunismo (T.E.R.M.C.), leg. 13033. Y Sec. Masoneria Exp. 18, leg. 21.

36 AHN. -TERMC, leg. 30364. Y Sec. Masoneria, Exp. 28, leg. 625.

37 Sec. Masonería, Exp. 28, leg. 625. 
había partida de defunción por lo que se cierra el proceso provisional por «presunto fallecimiento" como queda dicho. De nuevo la contradicción. Solo se imaginan su pertenencia por un «chivato» y después cierran el proceso provisionalmente a pesar de conocer su muerte por documento del Ejército ${ }^{38}$.

\section{Lorenzo Aguirre Sánchez}

Fue incoado el expediente el 8 de noviembre de 1946, dándose la sentencia el 24 de mayo del año siguiente. El expedientado fue Comisario de Investigación y Vigilancia en Valencia durante la Guerra Civil, y allí se inició en la Logia Occidental n. ${ }^{\circ} 1$ el 12 de febrero de 1937. Luego se trasladó a Barcelona «cuando el Gobierno rojo se instaló en dicha Capital», paso luego a Francia. Tras regresar clandestinamente a España fue hecho prisionero «juzgado por su actuación durante el periodo rojo» que consistía en haberse afiliado al partido comunista «procurando por todos los medios a su alcance, atraer adeptos para el mismo entre los elementos del cuerpo" y ejecutado aunque se ignoraba lugar y fecha según indica la Dirección General de Seguridad, pero constaba en la Dirección General de Prisiones que había sido ejecutado en la provincial de Madrid el 6 de octubre de 1942, ante todo ello se decidió el archivo provisional de las diligencias ${ }^{39}$.

\section{Manuel Añaza Dlaz}

La fecha de incoación de expediente es el 22 de noviembre de 1941, concluido el 30 de diciembre del mismo año por ignorarse paradero, aunque en el expediente se puede leer «que si bien no consta en Autos el fallecimiento... es del dominio público el hecho de su muerte, acaecído en el extranjero, extremo que en su dia fue ampliamente difundido, en razón a la triste celebridad alcanzada por el procesado como uno de los más caracterizados enemigos de la Patria». Se sabía que había muerto el 3 de noviembre y se prohibió «totalmente cualquier noticia relacionada» con él al día siguiente ${ }^{40}$, y en cambio el juez Sr. Peredas solicita requisitoria para que se publique en el Boletín Oficial del Estado para que comparezca con las penas reglamentarias si no escucha esta llamada.

Lógicamente se indica que tenía en la masonería el nombre simbólico de PLUTARCO perteneciendo a las logias Matritense e Hispano Americana n.o 2, y había sido denunciado por Luis Massip del Rey, José Casado Pons y Mariano Blasco Perdiguer ${ }^{4}$.

38 AHN. -TERMC, leg. 17069.

39 AHN. -TERMC, leg. 19014.

40 Archivo General de la Administración de Alcalá de Henares (A.G.A.), serie Fondode Cultura, caja n.o 349. Orden de censura de 4 de noviembre de 1940. Fue uno de los mas perseguidos por la prensa. ElNoticiero de Zaragoza le llamaba «anormal» y «monstruo», Vicente Gay, jefe de la Oficina de Prensa y Propaganda de Franco lo titulo «misero gusano» y el periodista González Ruano lo definía como «el mayor engendrode la Historia de España» en SINOVA, J. Op. cit., p. 200.

41 AHN. -TERMC. Leg. 490. 


\section{JOSÉ MIGUEL DELGADO IDARRETA}

Además lo denuncian como masón Angel de la Guardia Pi (6-V-1940), Dámaso Vélez González (9-V-1940), José Terrero Sánchez (V-1940), Roberto Maraury y Barredo (V1940), Luis García Galindo, etc.

Para constatar su pertenencia a la masonería se alude a la obra de F. Ferrari Billoch «La masonería al desnudo» donde aparece una fotocopia de su iniciación en la logia Matritense el 13 de marzo de 1932, a que fue citado en la página 9 del Boletín mensual de la gran Logia Española, y escritos de la Gran Logia Regional del Centro, del Gran Consejo Federal simbólico, etc. Por supuesto su afiliación política como miembro de Izquierda Republicana es también objeto de la acusación y para ello se incluye en el informe una fotografía de Azaña con la siguiente dedicatoria «A las agrupaciones y afiliados de Izquierda Republicana, con afectuoso compañerismo. Enero, 1936. Manuel Azaña ${ }^{42}$.

\section{Santiago Casares Quiroga}

Se abrió expediente el 28 de julio de 1941 siendo concluido el 2 de setiembre de ese año al declarar al inculpado en rebeldía y como todos los anteriores se le acusa por no retractarse conforme determina la ley. Figura con el simbólico SAINT JUST en la Logia Hispano Americana n. 379 y Suevia n. 94 habiendo sido iniciado en la primera el 24 de octubre de 1917. Fue delatado por Plaza Vinuesa que hizo relato de las actividades de la masonería de 1925 a 1934 y por Nicolás Mínguez y Mínguez al retractarse en junio de 1940 a la vez que acusaba a Casares Quiroga. Lógicamente su pertenencia a la masonería y «la actividad netamente revolucionaría desarrollada en la política», no olvidemos que era el Jefe del Gobierno el 18 de julio de 1936, le llevan a ser condenado a reclusión mayor y accesorios correspondientes ${ }^{43}$.

Al igual que los anteriores entre las pruebas que se aportan figura el Carnet Masónico con su pertenencia a la Hispano Americana de los Valles de Madrid, su baja de la Gran Logia Regional del Sudeste de España en agosto de 1933, así como su título de maestro masón de 3 de mayo de 1918. Aparecen las correspondientes denuncias firmadas por Manuel Rosendo Monrubio, (29-X-1941), Lorenzo López Sáinz de Varanda (6-X1943), Matias Wirz Senni (20-X-1941), Julio Wonemburger Canosa (18-VIII-1941), etc., por supuesto su naturaleza izquierdista y haber sido Presidente del Gobierno del Frente Popular son razones políticas más que suficientes para su procesamiento entre otras razones políticas como desempeñar la Cartera de Marina, fundar en La Coruña el O.R.G.A., luego fusionado con Izquierda Republicana, etc. lo que supuso ser condenado por «delito consumado de masonería... a la pena de treinta años de reclusión mayor con sus accesorios de interdicción civil, inhabilitación absoluta...» ${ }^{44}$. 


\section{CONCLUSIÓN}

La masonería «que es un gran anhelo de sindicación colectiva, transmitida de padres a hijos, como piadoso legado de amor, que salva a los pueblos de la hipocresía, superstición y esclavitud... desinteresada y altruista por excelencia para dignificar la condición humana» como escribía Juan A. Salado ${ }^{45}$ se veía perseguida y acosada, se le imputaba incluso como hemos visto todos los males de España y el asesinato concreto de José Calvo Sotelo, que llevó aparejado el procesamiento de seis personas por el mero hecho de su «izquierdismo» y pertenecer a la masonería. Personas que sólo son un ejemplo de la sistemática represión jurisdicopolítica que el régimen de Franco instituyó incluso como forma de reacción aún terminada la Guerra Civil, a pesar de que incluso los masones habían solicitado la piedad y la comprensión para con los perdedores, pero el avance de los fascismos y la II. - Guerra Mundial no van a favorecer que durante el franquismo las cosas volvieran por sus cauces.

45 En Izquierda Republicana, de 7 de octubre de 1935. 
